Article

\title{
Power Control Design for Variable-Speed Wind Turbines
}

\section{Yolanda Vidal ${ }^{1, *}$, Leonardo Acho ${ }^{1}$, Ningsu Luo ${ }^{2}$, Mauricio Zapateiro ${ }^{1}$ and Francesc Pozo $^{1}$}

${ }^{1}$ Control Dynamics and Applications Research Group (CoDAlab), Barcelona College of Industrial Engineering, Polytechnic University of Catalonia, Comte d'Urgell, 187, Barcelona 08036, Spain; E-Mails: leonardo.acho@upc.edu (L.A.); mauricio.zapateiro@upc.edu (M.Z.); francesc.pozo@upc.edu (F.P.)

${ }^{2}$ Modal Intervals and Control Engineering Research Group, Department of Electrical Engineering, Electronics and Automatic Control, Institute of Informatics and Applications, University of Girona, Campus Montilivi, P-IV, Girona 17071, Spain; E-Mail: ningsu.luo@udg.edu

* Author to whom correspondence should be addressed; E-Mail: yolanda.vidal@upc.edu; Tel.: +34-93-413-7309; Fax: +34-93-413-7401.

Received: 25 June 2012; in revised form: 3 August 2012 / Accepted: 3 August 2012 /

Published: 13 August 2012

\begin{abstract}
This paper considers power generation control in variable-speed variable-pitch horizontal-axis wind turbines operating at high wind speeds. A dynamic chattering torque control and a proportional integral (PI) pitch control strategy are proposed and validated using the National Renewable Energy Laboratory wind turbine simulator FAST (Fatigue, Aerodynamics, Structures, and Turbulence) code. Validation results show that the proposed controllers are effective for power regulation and demonstrate high-performances for all other state variables (turbine and generator rotational speeds; and smooth and adequate evolution of the control variables) for turbulent wind conditions. To highlight the improvements of the provided method, the proposed controllers are compared to relevant previously published studies.
\end{abstract}

Keywords: wind turbine; variable-pitch; power regulation 


\section{Introduction}

Motivated by the high dependence that the global economy has on fossil fuels and environmental concerns, focus on alternative methods of electricity generation is increasing. In this trend towards the diversification of the energy market, wind power is the fastest growing sustainable energy resource [1].

Wind turbines with rudimentary control systems that aim to minimize cost and maintenance of the installation have predominated for a long time [1]. More recently, the increasing size of the turbines and the greater penetration of wind energy into the utility networks of leading countries have encouraged the use of electronic converters and mechanical actuators. These active devices incorporate extra degrees of freedom into the design, allowing for active control of the captured power. Static converters, used as an interface to the electric grid, enable variable-speed operation, at least up to rated speed. Due to external perturbations, such as random wind fluctuations, wind shear and tower shadows, variable speed control seems to be a good option for optimizing the operation of wind turbines [2]. Wind energy conversion systems are challenging from the control system viewpoint. Wind turbines inherently exhibit nonlinear dynamics and are exposed to large cyclic disturbances that may excite the poorly damped vibration modes of the drive-train and tower, see [1,3]. Additionally, it is difficult to obtain mathematical models that accurately describe the dynamic behavior of wind turbines because of the particular operating conditions. Moreover, this task is even more involved due to the current tendency towards larger and more flexible wind turbines. The lack of accurate models must be countered by robust control strategies capable of securing stability and certain performance features despite model uncertainties. The control problems are even more challenging when turbines are able to operate at variable speeds and pitch, see [4-6]. The best use of this type of turbine can only be achieved with several controllers, see $[7,8]$.

A new control strategy for variable-speed, variable-pitch horizontal-axis wind turbines (HAWTs) is proposed in this paper. This control is obtained with a nonlinear dynamic chattering torque control strategy and a proportional integral (PI) control strategy for the blade pitch angle. This new control structure allows for a rapid transition of the wind turbine generated power between different desired values. This implies that it is possible to increase or decrease the WT power production with consideration of the power consumption on the network. This electrical power tracking is ensured with high-performance behaviors for all other state variables: including turbine and generator rotational speeds; and smooth and adequate evolution of the control variables.

This paper is organized as follows. In Section 2, the wind turbine modeling is presented. Section 3 briefly describes the National Renewable Energy Laboratory (NREL) wind turbine simulator FAST code [9]. The pitch and torque controllers are then presented in Section 4. Finally, in Section 5, the proposed controllers are validated with the FAST aeroelastic wind turbine simulator and their performance is compared to the controllers proposed in $[10,11]$ to highlight the improvements of the provided method.

\section{System Modeling}

The wind turbine consists of a rotor assembly, gear-box, and generator. The wind turbine rotor extracts the energy from the wind and converts it into mechanical power. A simplified model of the 
rotor was employed in [12-14]. This model assumes an algebraic relation between the wind speed and the extracted mechanical power, described with the following equation

$$
P_{m}(u)=\frac{1}{2} C_{p}(\lambda, \beta) \rho \pi R^{2} u^{3}
$$

where $\rho$ is the air density, $R$ is the radius of the rotor, $u$ is the wind speed, $C_{p}$ is the power coefficient of the wind turbine, $\beta$ is the pitch angle, and $\lambda$ is the tip-speed ratio given by

$$
\lambda=\frac{R \omega_{r}}{u}
$$

where $\omega_{r}$ is the rotor speed. Thus, changes in the wind speed or rotor speed produce changes in the tip-speed ratio, leading to power coefficient variation; thus, the generated power is affected. The aerodynamic torque coefficient is related to the power coefficient as follows,

$$
P_{m}=\omega_{r} T_{a}
$$

the aerodynamic torque expression is described as

$$
T_{a}=\frac{1}{2} C_{q}(\lambda, \beta) \rho \pi R^{3} u^{2}
$$

where

$$
C_{q}(\lambda, \beta)=\frac{C_{p}(\lambda, \beta)}{\lambda}
$$

For a perfectly rigid low-speed shaft, a single-mass model for a wind turbine can be considered [10,15-17],

$$
J_{t} \dot{\omega}_{r}=T_{a}-K_{t} \omega_{r}-T_{g}
$$

where $J_{t}$ is the turbine total inertia $\left(\mathrm{kg} \mathrm{m}^{2}\right), K_{t}$ is the turbine total external damping $\left(\mathrm{Nm} \mathrm{rad}^{-1} \mathrm{~s}\right), T_{a}$ is the aerodynamic torque $(\mathrm{Nm})$, and $T_{g}$ is the generator torque $(\mathrm{Nm})$. The scheme of the one-mass model is provided in Figure 1.

Figure 1. One-mass model of a wind turbine.

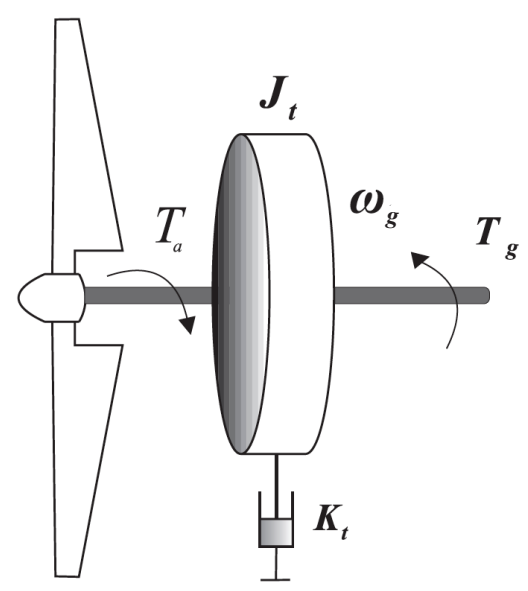




\section{Brief Simulator Description (FAST)}

The FAST code [9] is a comprehensive aeroelastic simulator capable of predicting the extreme and fatigue loads of two- and three-bladed HAWTs. This simulator was chosen for validation because, in 2005, it was evaluated by Germanischer Lloyd WindEnergie and found suitable for the calculation of onshore wind turbine loads for design and certification [18]. An interface between FAST and Simulink was also developed with MATLAB $^{\circledR}$, enabling users to implement advanced turbine controls in Simulink ${ }^{\circledR}$ a convenient block diagram form. The FAST subroutines are linked with a Matlab standard gateway subroutine so the FAST motion equations (in an S-function) can be incorporated in a Simulink model. This introduces tremendous flexibility for wind turbine control implementation during simulation. Generator torque, nacelle yaw, and pitch control modules can be designed in the Simulink environment and simulated while using the complete nonlinear aeroelastic wind turbine equations of motion, which are available in FAST. The wind turbine block contains the S-function block with the FAST motion equations and blocks that integrate the degree-of-freedom accelerations to obtain velocities and displacements. Thus, the equations of motion are formulated in the FAST S-function and solved using one of the Simulink solvers.

\section{Control Strategy}

The developed MATLAB ${ }^{\circledR}$ interface between FAST and Simulink has allowed us to implement the proposed torque and pitch controls in Simulink ${ }^{\circledR}$ convenient block diagram form. The open loop FAST simulink model is provided in Figure 2.

Figure 2. Simulink open-loop model.
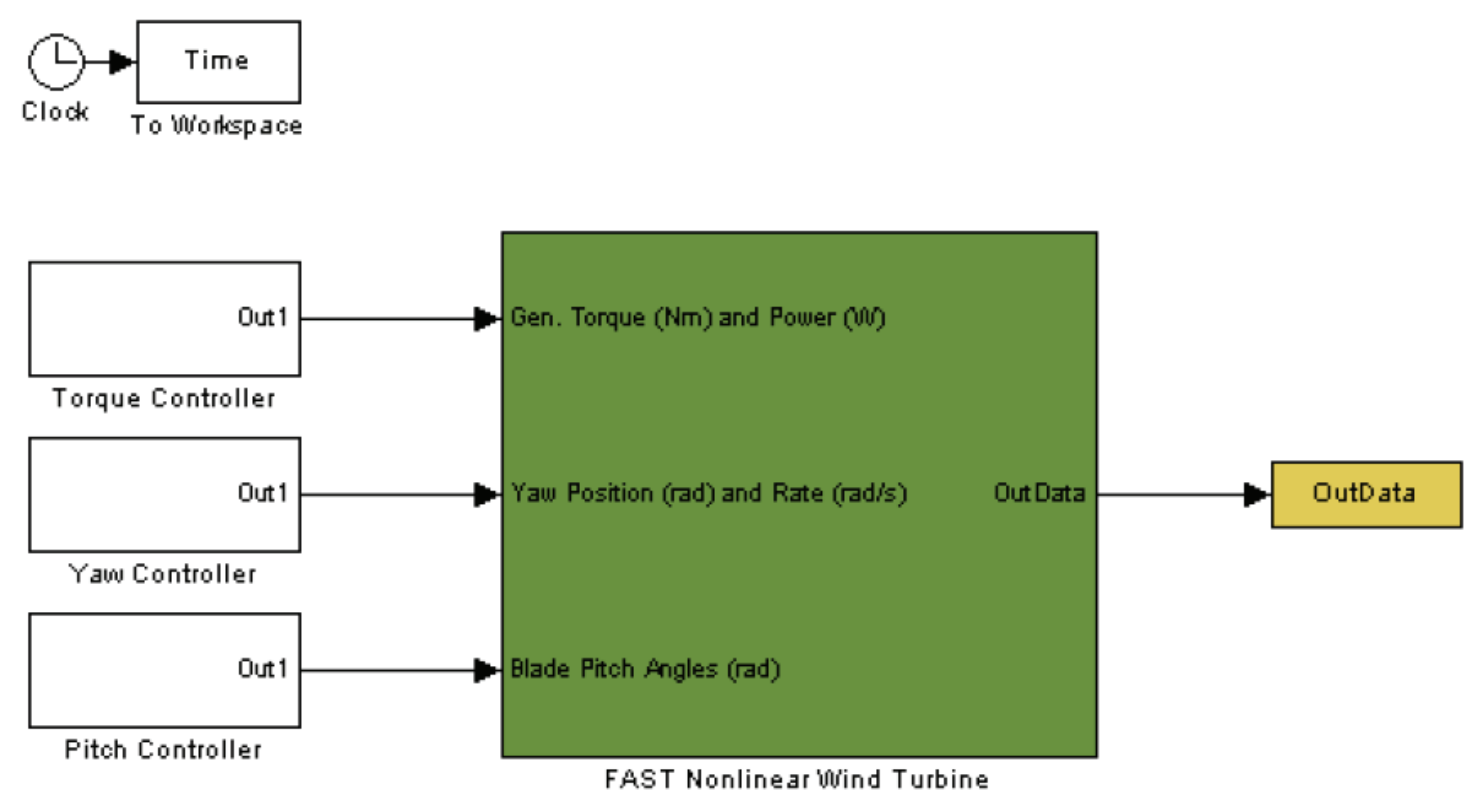

The next sections present the proposed nonlinear dynamic torque and linear pitch controller designs. 


\subsection{Torque Controller}

The electrical power-tracking error is defined as

$$
e=P_{\mathrm{e}}-P_{\text {ref }}
$$

where $P_{\mathrm{e}}$ is the electrical power and $P_{\text {ref }}$ is the reference power. We impose a first-order dynamic to this error,

$$
\dot{e}=-a e-K_{\alpha} \operatorname{sgn}(e) \quad a, K_{\alpha}>0
$$

and consider that the electrical power is described as $[10,15,17,19]$

$$
P_{\mathrm{e}}=\tau_{c} \omega_{g}
$$

where $\tau_{c}$ is the torque control and $\omega_{g}$ is the generator speed. By substitution of Equations (1) and (3) into (2), and assuming that $P_{\text {ref }}$ is a constant function, we obtain

$$
\dot{\tau}_{c} \omega_{g}+\tau_{c} \dot{\omega}_{g}=-a\left(\tau_{c} \omega_{g}-P_{\text {ref }}\right)-K_{\alpha} \operatorname{sgn}\left(P_{\mathrm{e}}-P_{\text {ref }}\right)
$$

which, can also be written as

$$
\dot{\tau}_{c}=\frac{-1}{\omega_{g}}\left[\tau_{c}\left(a \omega_{g}+\dot{\omega}_{g}\right)-a P_{\text {ref }}+K_{\alpha} \operatorname{sgn}\left(P_{\mathrm{e}}-P_{\text {ref }}\right)\right]
$$

Theorem 4.1 The proposed controller 4 ensures finite time stability [20]. Moreover, the settling time can be chosen by properly defining the values of the parameters a and $K_{\alpha}$.

Proof We now present the Lyapunov function

$$
V=\frac{1}{2} e^{2}
$$

Then, based on Equation (2), the time derivative along the trajectory of the system yields

$$
\dot{V}=e \dot{e}=e\left(-a e-K_{\alpha} \operatorname{sgn}(e)\right)=-a e^{2}-K_{\alpha}|e|<0
$$

Thus, $V$ is globally positive definite and radially unbounded, while the time derivative of the Lyapunov-candidate-function is globally negative definite; so the equilibrium is proven to be globally asymptotically stable. Moreover, finite time stability can be proven. Equation (6) can be written as

$$
\dot{V} \leq-K_{\alpha}|e|=-K_{\alpha} \sqrt{2} \sqrt{V}
$$

Thus, $\dot{V}+K_{\alpha} \sqrt{2} \sqrt{V}$ is negative semidefinite and Theorem 1 in [20] can be applied to conclude that the origin is a finite time stable equilibrium. Furthermore, from [20], the settling time function $t_{s}$ is described as

$$
t_{s} \leq \frac{1}{K_{\alpha} \sqrt{2}}(V)^{1 / 2}
$$

and using Equation (5) leads to

$$
t_{s} \leq \frac{e}{K_{\alpha}}
$$


For $K_{\alpha}=0$, an exponentially (but not finite time) stable controller is obtained

$$
\dot{e}=-a e
$$

Next, we compute an approximate settling time (for practical purposes) for the exponentially stable controller to choose a settling time that is much smaller for the finite time stable approach. For this purpose, we compare the exponentially stable error dynamic, Equation (8), with the simplest resistor-capacitor (RC) circuit. This circuit is composed of one resistor, $R$, and one capacitor, $C$, in series. When a circuit only consists of a charged capacitor and a resistor, the capacitor will discharge its stored energy through the resistor. The voltage, $v$, across the capacitor, which is time dependent, can be obtained with Kirchhoff's current law. This results in the linear differential equation described as

$$
C \dot{v}+\frac{v}{R}=0
$$

It is well known that the solution of this first order differential equation is an exponential decay function,

$$
v(t)=v_{0} e^{\frac{-t}{R C}}
$$

where $v_{0}$ is the capacitor voltage at time $t=0$. The time required for the voltage to decrease to $v_{0} / e$ is the time constant, $\tau=R C$. The capacitor is considered to be fully discharged (0.7\%) after approximately $5 \tau \mathrm{s}$, as described in [21].

Comparison of the RC circuit ODE, Equation (9), with the exponentially stable error dynamic, Equation (8), leads to the equality $a=\frac{1}{R C}$, where $\tau=1 / a$. An exponentially stable error dynamic will require $5 \tau$ to achieve $(0.7 \%$ error) the desired value. Because our proposed controller is finite time stable, from Equation ( 7$)$ we can choose parameter values to obtain the desired value in $0.2(5 \tau) \mathrm{s}$. Thus, assuming values close to $t=0$, the error is bounded by $|e|<1.5 \times 10^{6}$ (which is the rated power of the wind turbine)

$$
t_{s} \leq \frac{1.5 \times 10^{6}}{K_{\alpha}}<0.2(5 \tau)=0.2\left(5 \frac{1}{a}\right)
$$

For $a=1$, the estimated settling time is less than one second,

$$
t_{s} \leq \frac{1.5 \times 10^{6}}{K_{\alpha}}<1
$$

and, by rearranging terms, the value of $K_{\alpha}$ should be,

$$
K_{\alpha}>1.5 \times 10^{6}
$$

Note that Equation (4) depends on $\dot{\omega}_{g}$. One way to compute this derivative is to use the one-mass model of a wind turbine that is presented in Section 2, in which all of the following WT parameters are required: turbine total inertia, turbine total external damping, aerodynamic torque, generator torque in rotor side, and gearbox ratio. Another way to compute this derivative is to use the estimator proposed in [22] (transfer function in the Laplace domain),

$$
\frac{s}{0.1 s+1}
$$


Input to Equation (11) is $\omega_{g}$ and the output is an estimation of $\dot{\omega}_{g}$.

The proposed simple nonlinear torque control Equation (4) does not require information from the turbine total external damping or the turbine total inertia. This control only requires the generator speed and electrical power of the WT. Thus, our proposed controller used with Equation (11), to approximate $\dot{\omega}_{g}$, requires few WT parameters. By contrast, most of the torque controllers in the literature [10,15-17] require many WT parameters, which restricts controller applicability when not all of the required parameters are available.

\subsection{Pitch Controller}

To assist the torque controller with regulating the wind turbine electric power output, while avoiding significant loads and maintaining the rotor speed within acceptable limits, a pitch proportional integral (PI) controller is added to the rotor speed tracking error:

$$
\beta=K_{p}\left(\omega_{r}-\omega_{n}\right)+K_{i} \int_{0}^{t}\left(\omega_{r}-\omega_{n}\right) d t, \quad K_{p}>0, K_{i}>0
$$

where $\omega_{r}$ is the rotor speed and $\omega_{n}$ is the nominal rotor speed, at which the rated electrical power of the wind turbine is obtained. To disable the proportional term when $\omega_{r}<\omega_{n}$, the final proposed controller is described with the following expression

$$
\beta=\frac{1}{2} K_{p}\left(\omega_{r}-\omega_{n}\right)\left[1+\operatorname{sgn}\left(\omega_{r}-\omega_{n}\right)\right]+K_{i} \int_{0}^{t}\left(\omega_{r}-\omega_{n}\right) d t, \quad K_{p}>0, K_{i}>0
$$

\section{Simulation Results}

Numerical validations with FAST on Matlab-Simulink were performed with the NREL WP 1.5-MW wind turbine. The wind turbine characteristics are summarized in Table 1.

Table 1. Wind Turbine Characteristics.

\begin{tabular}{lc}
\hline Number of blades & 3 \\
Height of tower & $82.39 \mathrm{~m}$ \\
Rotor diameter & $70 \mathrm{~m}$ \\
Rated power & $1.5 \mathrm{MW}$ \\
Gearbox ratio & 87.965 \\
Nominal rotor speed $\left(\omega_{n}\right)$ & $20 \mathrm{rpm}$ \\
\hline
\end{tabular}

The wind inflow for the simulations is shown in Figure 3. A variable reference set point is imposed on the WT electrical power. When the wind park manager requires a given electrical power, he/she must dispatch this reference over different wind turbines and impose a variable reference for each turbine to meet a specific request for the grid. This wind inflow, for the simulated NREL WP 1.5-MW wind turbine, reaches wind speeds that are above the rated power operating conditions. From Figure 3, the rated wind 
speed for the wind turbine is $11.8 \mathrm{~m} / \mathrm{s}$, which coincides with the mean wind speed profile. Figure 3 also shows the reference power (right y-axes).

Figure 3. Wind speed profile with a mean of $11.8 \mathrm{~m} / \mathrm{s}$ that corresponds to the rated wind speed of the WT (left y-axes). Reference power (right y-axes).

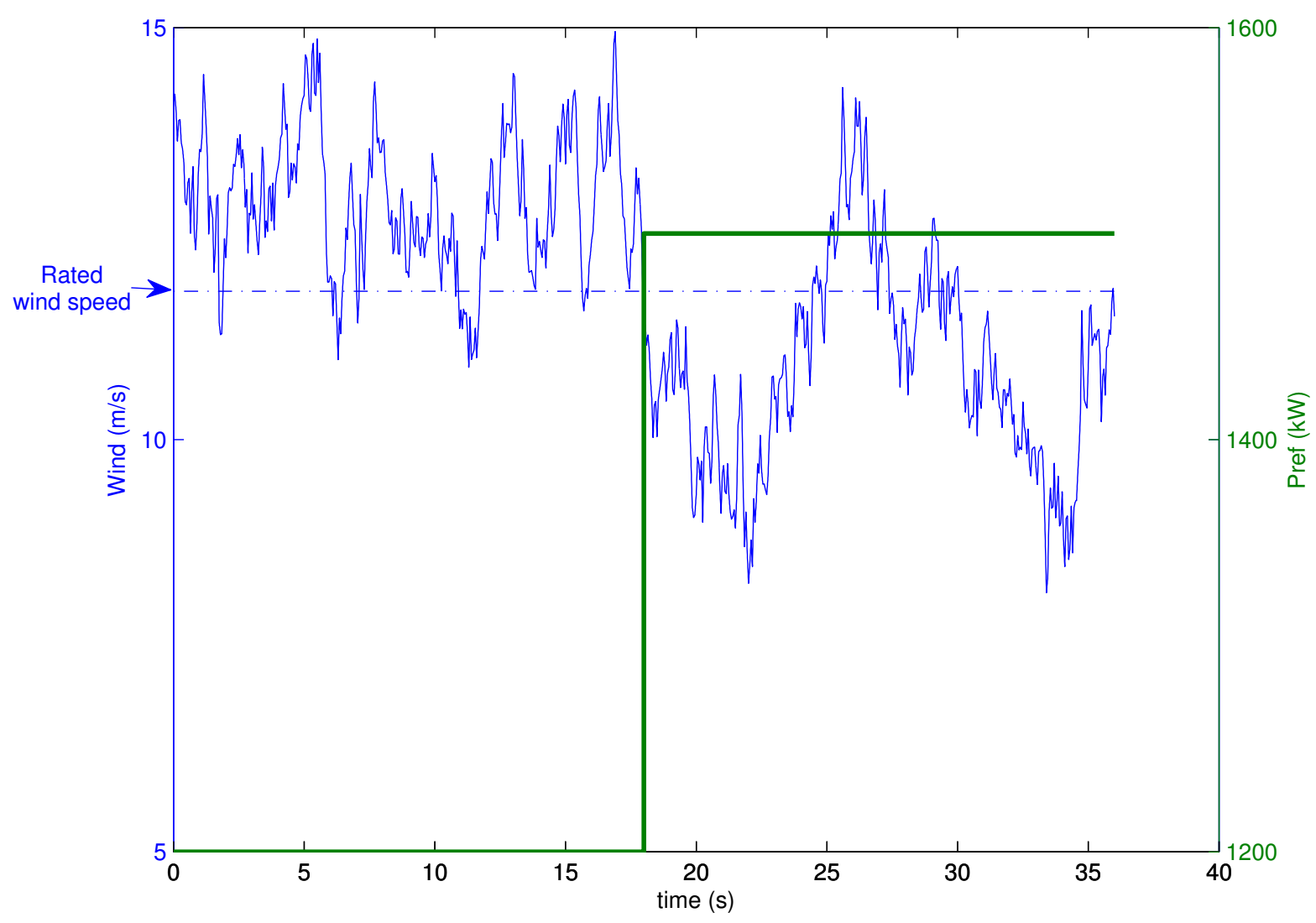

\subsection{Torque and Pitch Control}

The FAST simulator outputs with torque and pitch control are computed with $a=1, K_{p}=1, K_{i}=1$ and two values for $K_{\alpha}$ (different settling times), which are $K_{\alpha}=1.5 \times 10^{6}$ and $K_{\alpha}=1.5 \times 10^{5}$. These results are compared to those obtained with the controllers that were proposed by [10] (Bukhezzar's controller) and [11] (Jonkman's controller).

For all the tested controllers, the rotor speed, as shown in Figure 4, is near its nominal value of (20 rpm) due to the pitch control action.

From Figure 5, with the Boukhezzar controller, an exponential convergence is observed and the desired value is reached in approximately $5 \mathrm{~s}$ when the reference electrical power is changed. By contrast, with the Jonkman controller, an almost perfect power regulation is obtained; however, this torque controller generates high loads that can exceed the design load, which will be shown later. Our proposed controller has an intermediate behavior between Jonkman's and Boukhezzar's controllers. The electrical power follows the reference, independently of the wind fluctuations, with a settling time of one second, as can be expected [see Equation (10)] when using parameter $K_{\alpha}=1.5 \times 10^{6}$. When parameter $K_{\alpha}=1.5 \times 10^{5}$ is used, similar results are obtained but the settling time is increased. Our controller allows for selection of the settling time to obtain a controller that is closer to Jonkman's or Boukhezzar's 
controllers. However, for any given settling time, our controller more precisely reaches the reference power compared to the Boukhezzar's controller because it has finite convergence. This trend can be seen in the magnified image of Figure 5.

Figure 4. Rotor speed.

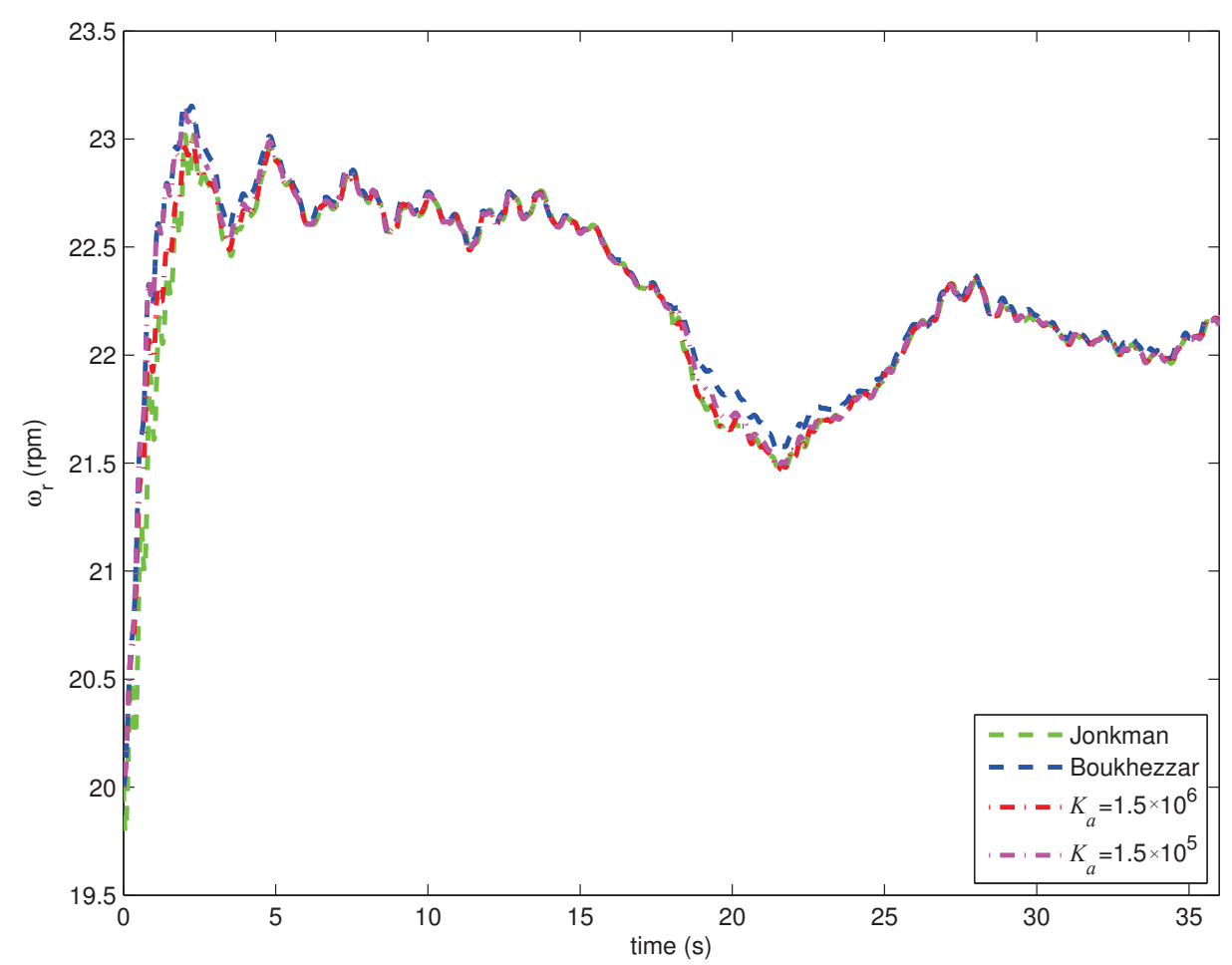

Figure 5. Power output.

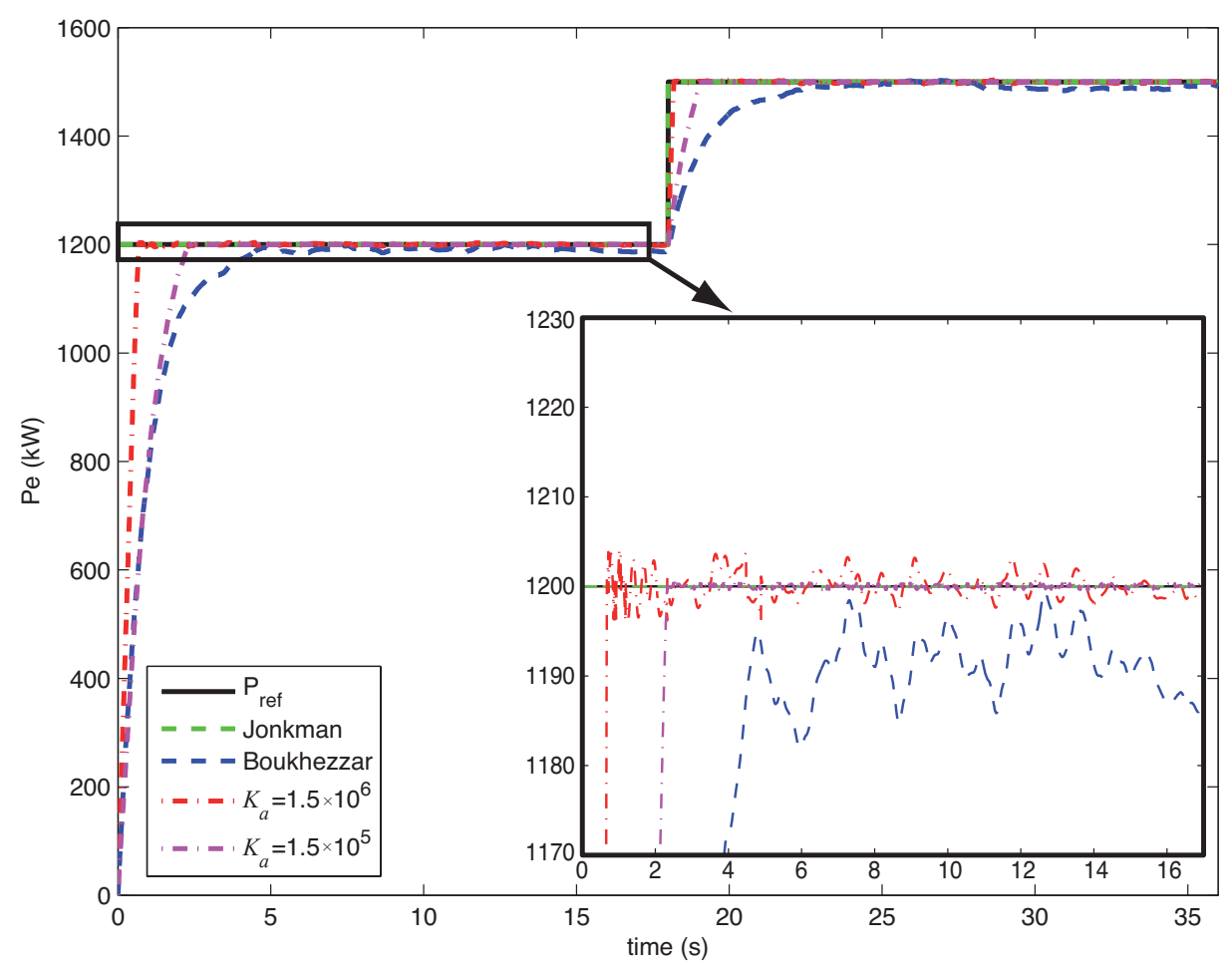


Typical maximum pitch rates range from $18 \%$ for $600 \mathrm{~kW}$ research turbines to $8 \% \mathrm{~s}$ for $5 \mathrm{MW}$ turbines [23]. From Figure 6, for all the tested controllers, the blade pitch angle is always within the authorized variation domain without exceeding a variation of $10 \%$ s.

Figure 6. Pitch control.

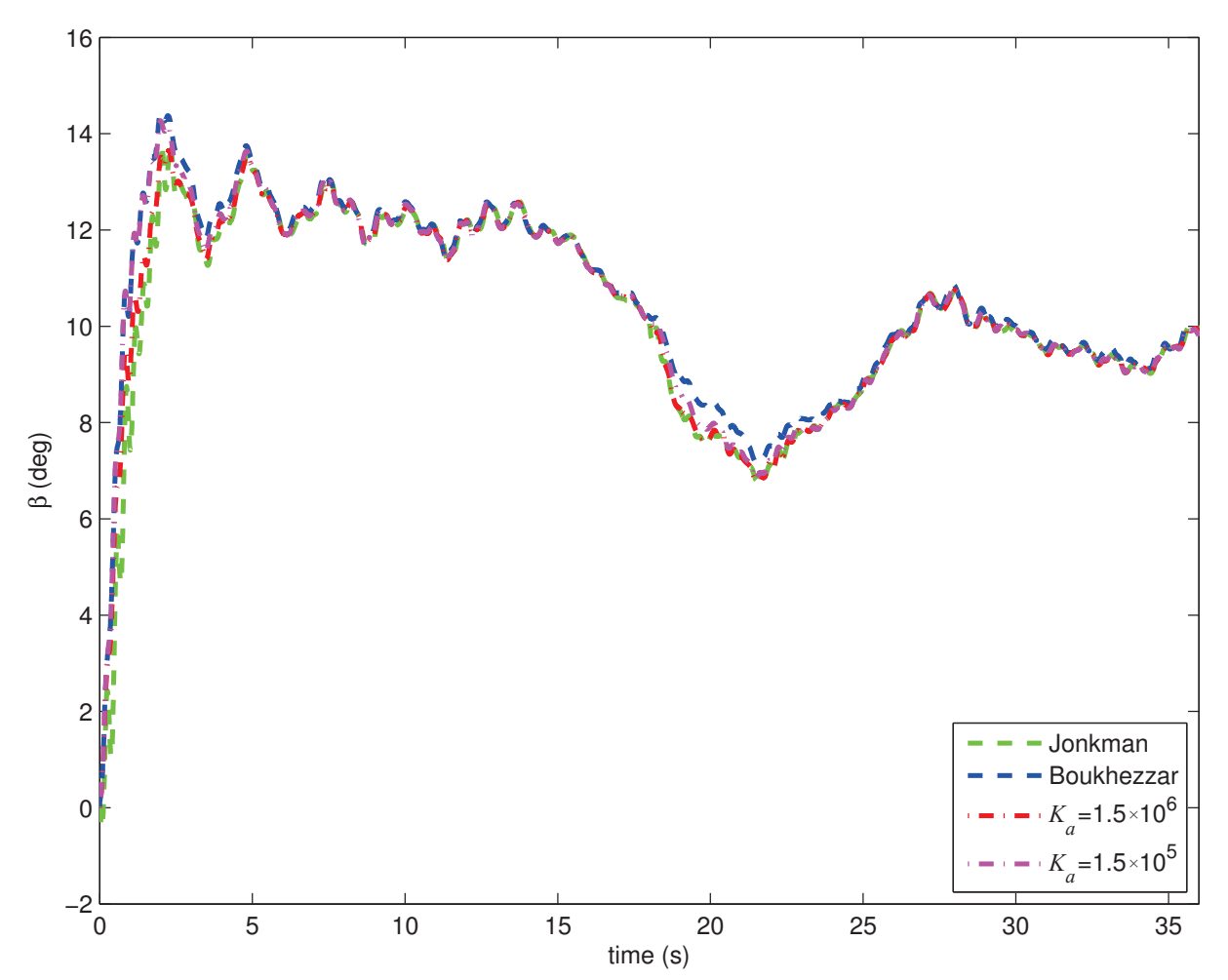

From Figure 7, the torque action of the proposed controller is smooth and achieves reasonable values, similar to those obtained by the Jonkman and Boukhezzar controllers. The generator may not be able to supply the desired electro-mechanic torque depending on the operating conditions. To avoid this excessive overloading, the torque control should be saturated to a maximum of $10 \%$ above the rated value, or $7.7 \mathrm{kN} \cdot \mathrm{m}$, see [11]. This value is represented in Figure 7; none of the tested controllers reach this extreme value.

The effect of loads on the control behavior is also important. The relevant loads to consider are the tower bottom side-to-side moment (shown in Figure 8), the drive shaft torsion (shown in Figure 9), the tower top/yaw bearing roll moment (shown in Figure 10), and the tower top/yaw bearing side-to-side shear force (shown in Figure 11). The Jonkman controller achieves high loads that almost exceed the design load in all cases, although it achieves nearly perfect power regulation. By contrast, Boukhezzar's controller uses intermediate loads but shows a poor performance for power regulation. Finally, our controller achieves the desired compromise between loads and the ability to track changes in the desired power. 
Figure 7. Torque control.

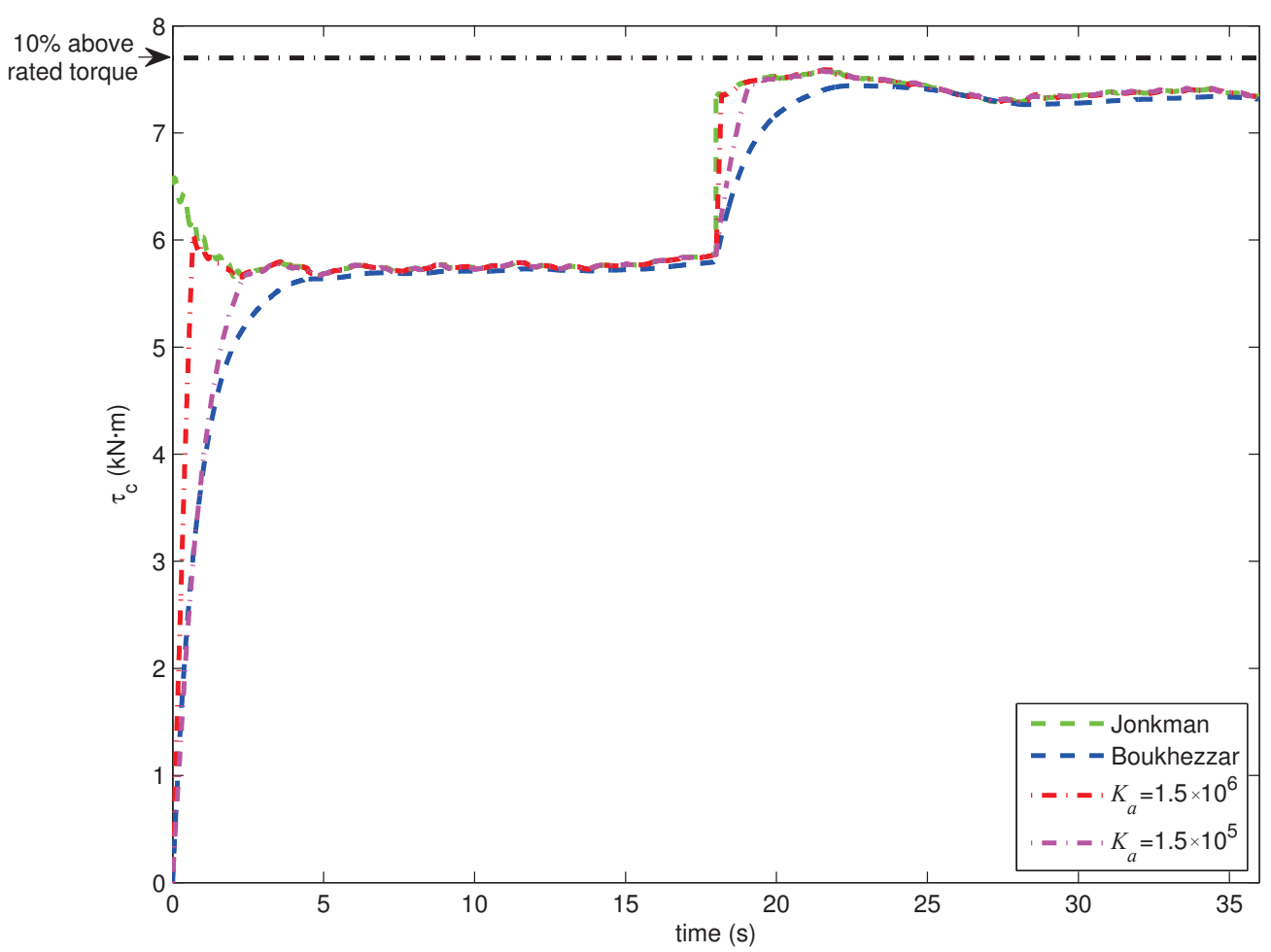

Figure 8. Tower bottom side-to-side moment.

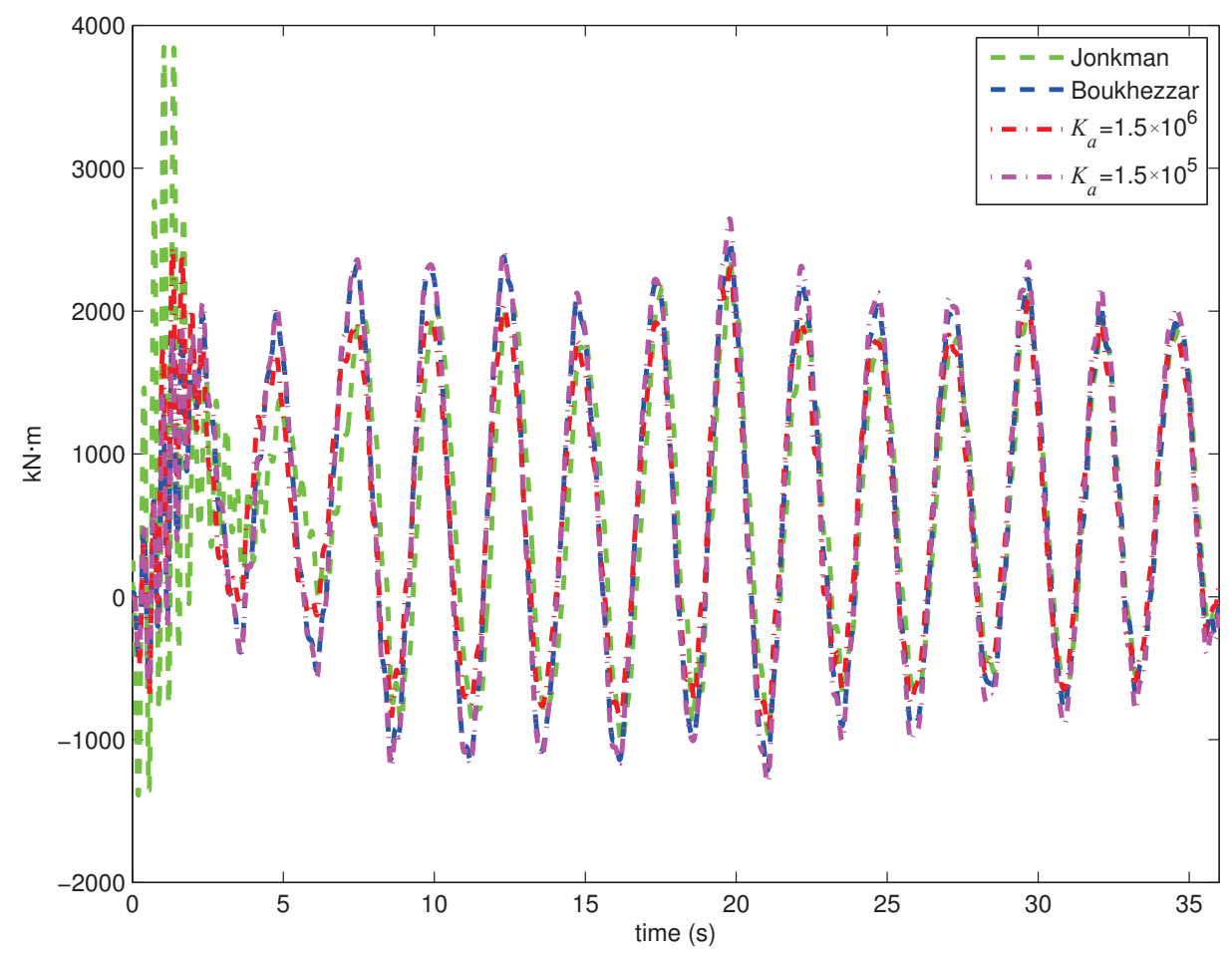


Figure 9. Drive shaft torsion.

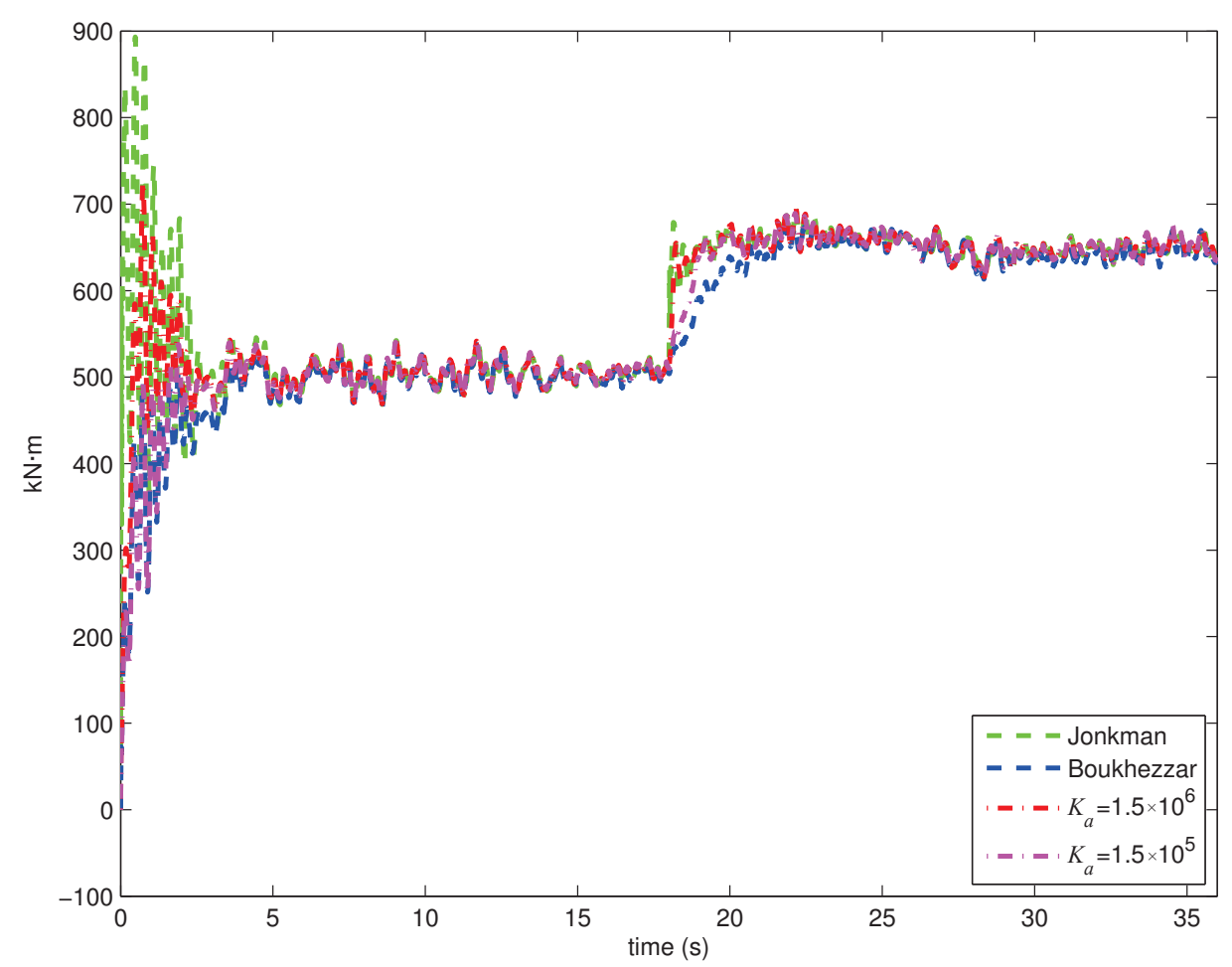

Figure 10. Tower top/yaw bearing roll moment.

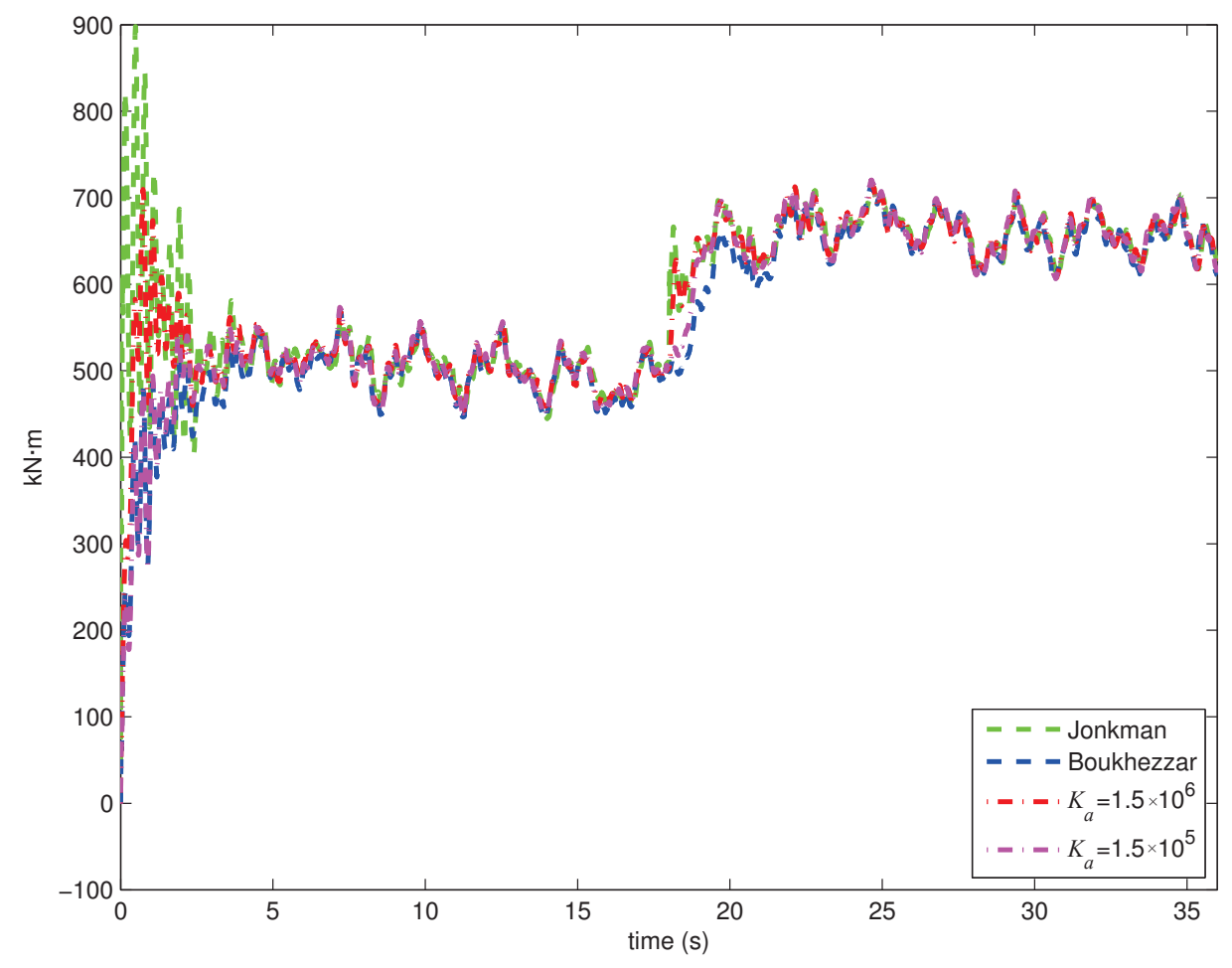


Figure 11. Tower top/yaw bearing side-to-side shear force.

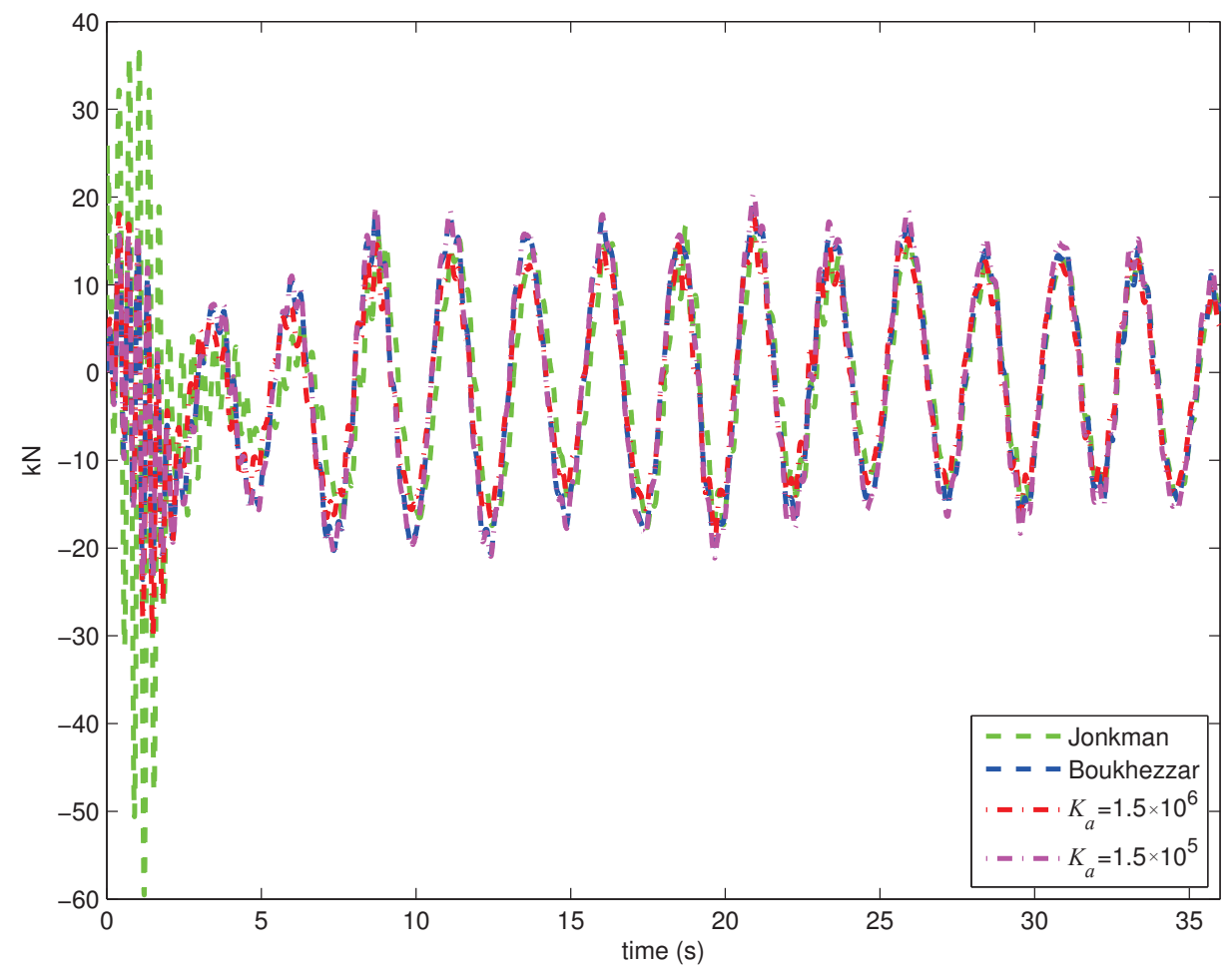

The blade edge-wise bending moment shown in Figure 12 is another relevant load, that, in this case, achieves similar results for all the tested controllers.

Figure 12. Blade edge-wise bending moment.

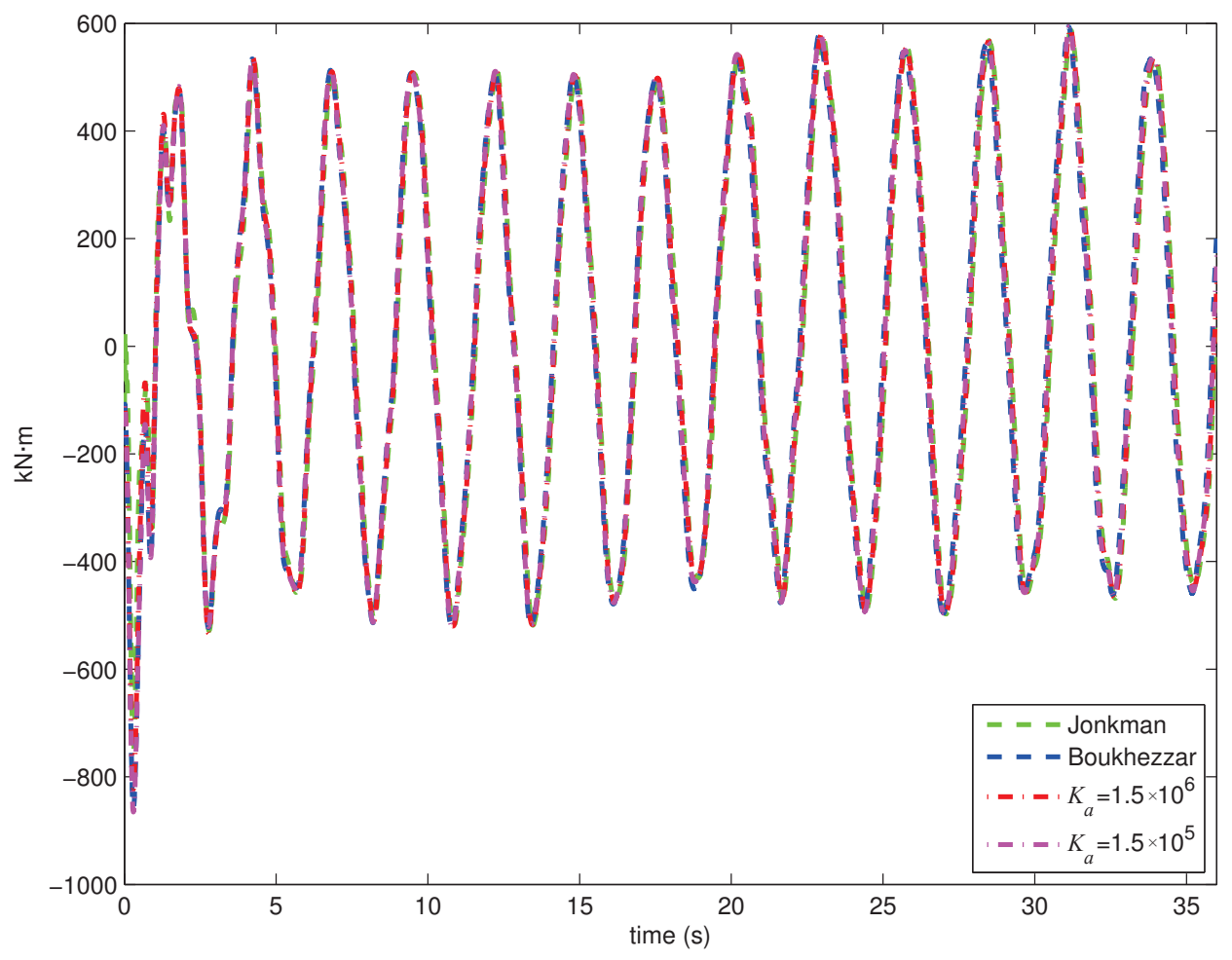


Finally the MatLab-based postprocessor MCrunch [24] for wind turbine data analysis has been used to perform a fatigue analysis. Table 2 shows the damage equivalent loads and Figure 13 shows the cumulative rainflow cycles of relevant loads from simulations up to $600 \mathrm{~s}$ and the reference power changing every $18 \mathrm{~s}$ between the values 1200 and $1500 \mathrm{~kW}$. The fatigue design SN slopes are extracted from the publication that documents the WindPACT turbines [25]. It is appreciated that the Jonkman's controller presents a marked fatigue variation for the first cumulative cycles per seconds for relevant loads as drive shaft torsion and tower top/yaw bearing roll moment. This agrees with the results observed in the previous section where this controller achieves high loads that almost exceed the design load.

Table 2. Table of damage-equivalent loads.

\begin{tabular}{lcccccc}
\hline & Units & SN Slope & $\boldsymbol{K}_{\boldsymbol{\alpha}}=\mathbf{1 . 5} \times \mathbf{1 0}^{\mathbf{5}}$ & $\boldsymbol{K}_{\boldsymbol{\alpha}}=\mathbf{1 . 5} \times \mathbf{1 0}^{\mathbf{6}}$ & Boukhezzar & Jonkman \\
\hline $\begin{array}{l}\text { Tower bottom } \\
\text { side-to-side }\end{array}$ & $(\mathrm{kN} \cdot \mathrm{m})$ & 3 & $1.255 \times 10^{3}$ & $1.195 \times 10^{3}$ & $1.174 \times 10^{3}$ & $1.418 \times 10^{3}$ \\
$\begin{array}{l}\text { Drive shaft } \\
\text { Tower top/yaw }\end{array}$ & $(\mathrm{kN} \cdot \mathrm{m})$ & 6.5 & $1.386 \times 10^{2}$ & $1.450 \times 10^{2}$ & $1.295 \times 10^{2}$ & $3.080 \times 10^{2}$ \\
$\begin{array}{l}\text { bearing roll } \\
\begin{array}{l}\text { Tower top/yaw } \\
\text { side-to-side }\end{array}\end{array}$ & $(\mathrm{kN} \cdot \mathrm{m})$ & 3 & $7.699 \times 10^{1}$ & $8.144 \times 10^{1}$ & $7.338 \times 10^{1}$ & $1.083 \times 10^{2}$ \\
$\begin{array}{l}\text { Blade edge- } \\
\text { wise bending }\end{array}$ & $(\mathrm{kN} \cdot \mathrm{k})$ & 3 & $1.555 \times 10^{1}$ & $1.501 \times 10^{1}$ & $1.473 \times 10^{1}$ & $1.443 \times 10^{1}$ \\
\hline & & 8 & $1.237 \times 10^{3}$ & $9.599 \times 10^{2}$ & $9.562 \times 10^{2}$ & $9.595 \times 10^{2}$ \\
\hline
\end{tabular}

Figure 13. Cumulative rainflow cycles.
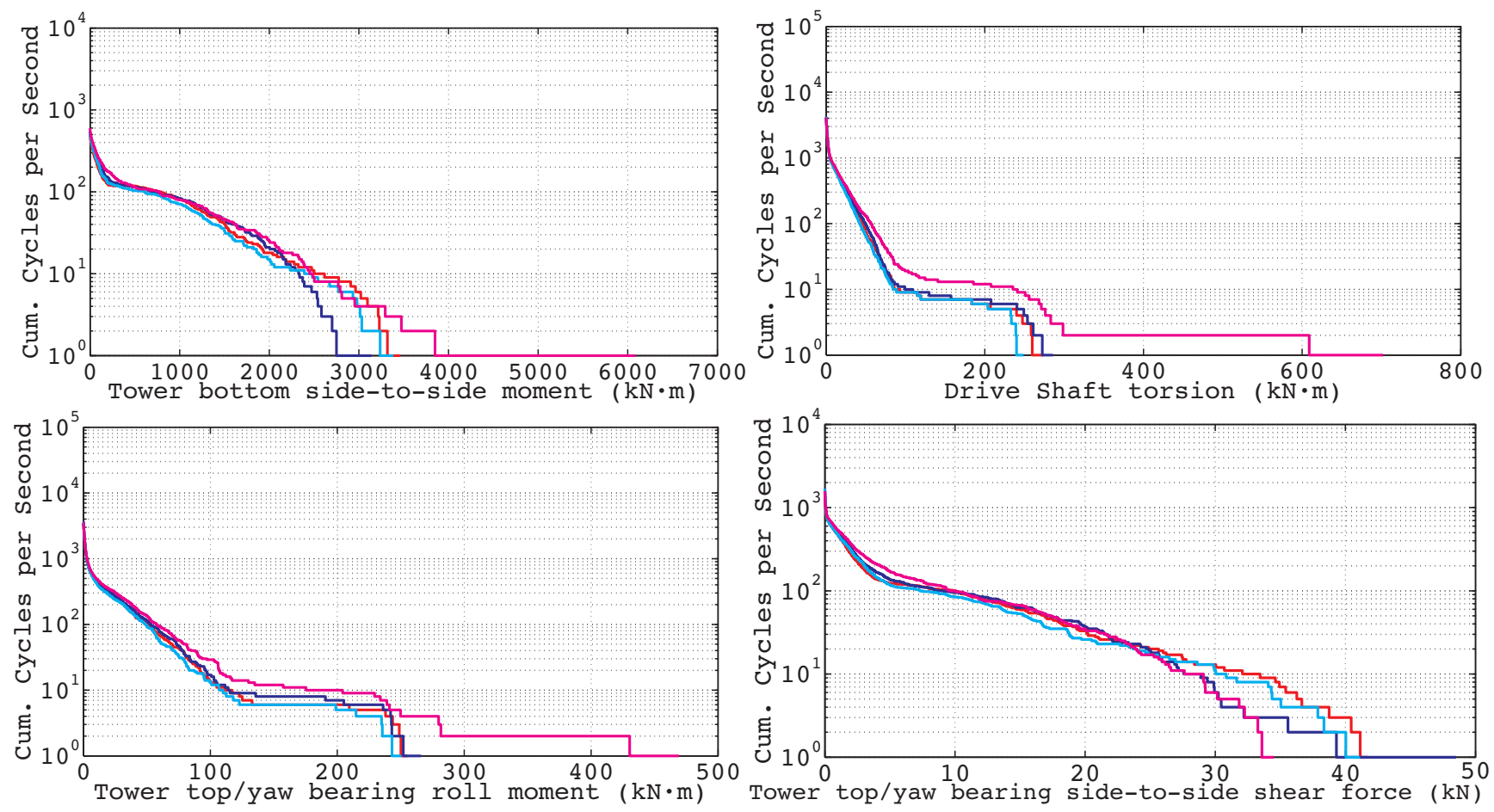
Figure 13. Cont.

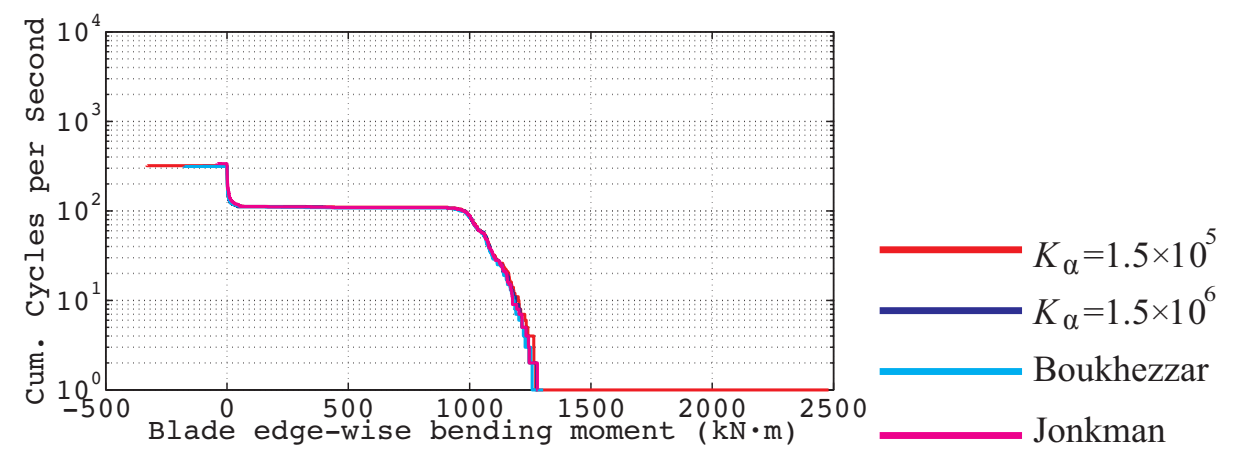

Figure 14. Power output with a periodic noise signal.

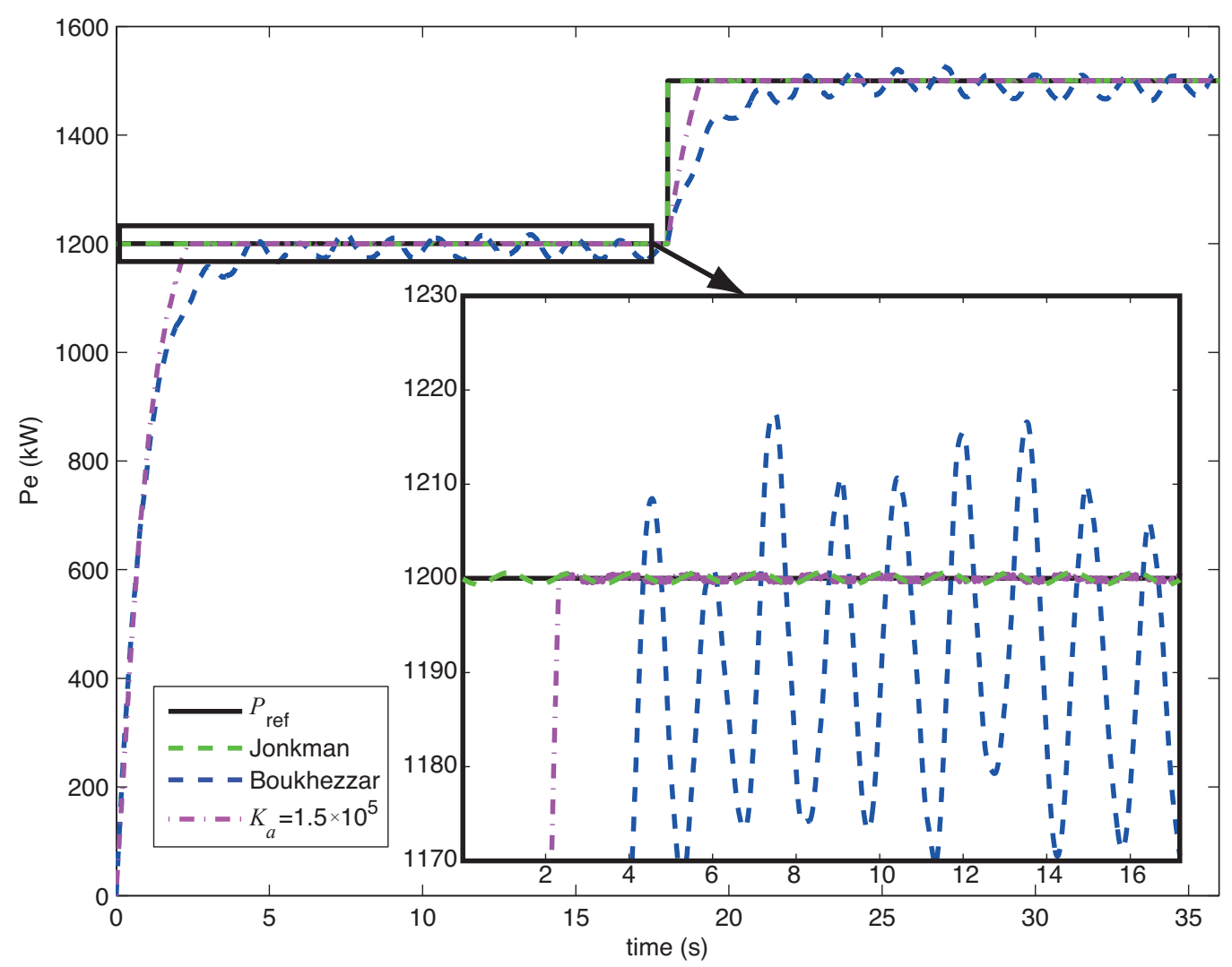

\subsection{Torque and Pitch Control with Noisy Signals}

As is typical for the utility-scale multi-megawatt wind turbines, the proposed generator torque and blade pitch controllers use the generator speed measurement as the sole feedback input. To consider signals noise (which is present in real applications), the generator speed measurement is modified by adding a sine wave with an amplitude of 0.1 and a frequency of $0 . \hat{6} \mathrm{~Hz}$ which is proportional (two times) to the nominal rotor speed. A periodic noise signal is first tested as periodic disturbances appear in rotating mechanical systems and it is important to reject them (see [26,27]). From the magnified image in Figure 14, our proposed controller is more robust to periodic noise signals than the other tested controllers. When comparing these results with Figure 5, Boukhezzar's controller is much more affected 
by the noise. Jonkman's controller is an almost perfect power regulation control; however, when noisy signals are used, the results are also affected. Jonkman's controller has a low-pass filter, as described in [11], but, in this case, the noisy signal is not filtered because it has a frequency of $0.25 \mathrm{~Hz}$, which is the corner frequency of the low-pass filter. A more suited filter can be used for Jonkman's controller and also certain filter types can be used with Boukhezzar's controller. However, our controller shows good performance without filters. Finally, a white noise signal is tested. From the magnified image in Figure 15, Boukhezzar's controller is again much more affected by the noise. Our proposed controller and Jonkman's controller have a similar performance in this case.

Figure 15. Power output with a white noise signal.

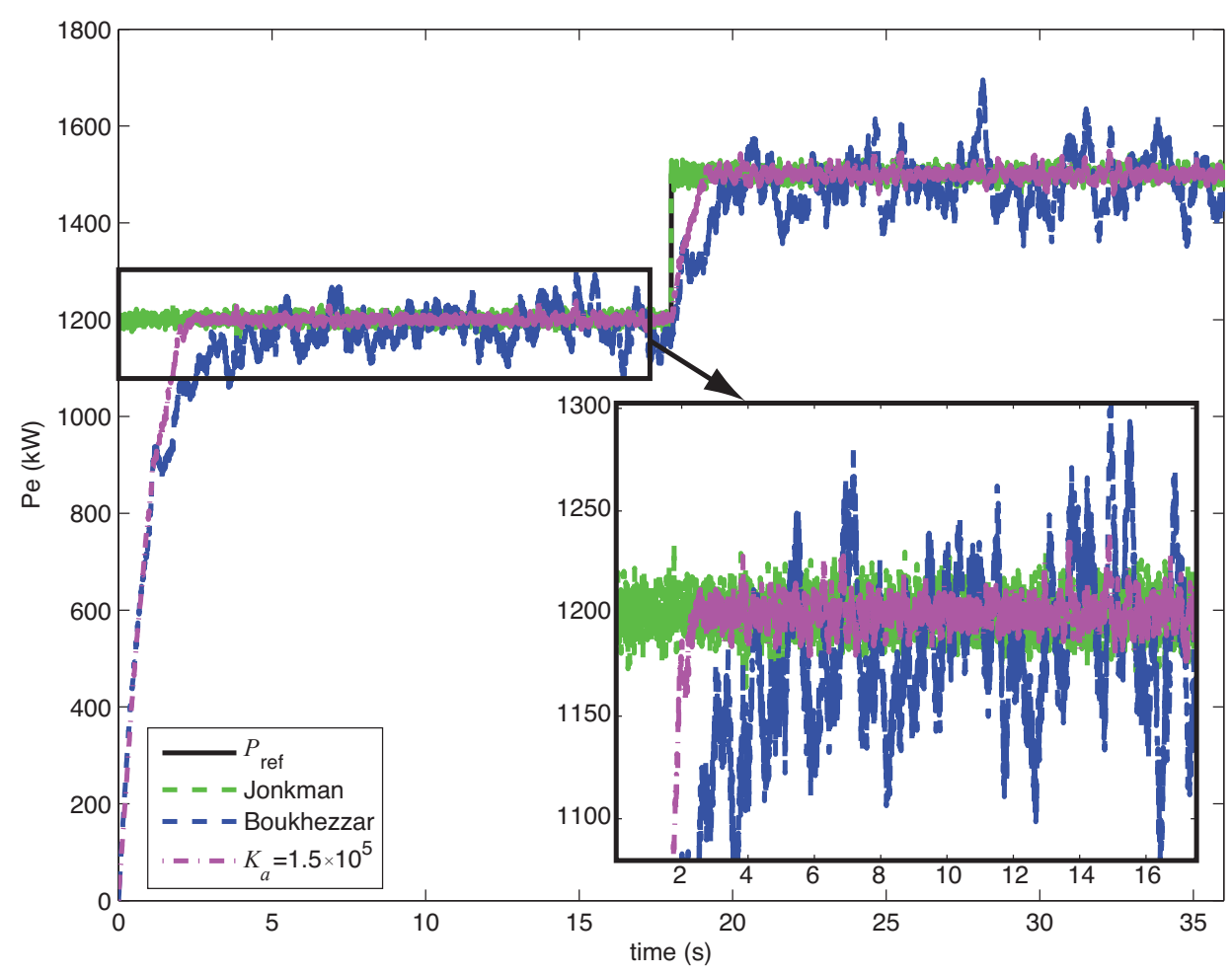

\section{Conclusions}

A WT controller for turbulent wind conditions is presented in this paper. The proposed controller achieves strong performances in rotor speed and electrical power regulation with acceptable control activity. These results show that the proposed controller allows the WT generated power to transit between different desired set values. This achievement implies that it is possible to increase or decrease the WT power production in response to the power consumption of the network and to participate in the primary grid frequency control, which allows for a higher level of wind penetration in electric networks without affecting the quality of the generated electric power. Finally, the improvements of the proposed controller versus the other tested strategies are described as follows:

- The proposed controller ensures finite time stability. Thus, the proposed controller more precisely reaches the desired power reference than exponentially stable controllers, such as [10]. 
- The proposed controller allows for selection of the settling time by properly defining the values of the parameters $a$ and $K_{\alpha}$ in Equation (4). Thus, our controller can be adjusted to obtain intermediate controllers with settling times that are closer to the Jonkman or Boukhezzar controller.

- The proposed simple nonlinear torque controller does not require information regarding the turbine total external damping or the turbine total inertia; it only requires the generator speed and electrical power of the WT. Thus, the proposed controller is easily applicable to other WTs. Using a simpler model than in [10], better results can be obtained.

- The proposed controller achieves the desired compromise between loads and the ability to track changes in the desired power.

- The proposed controller is more robust to periodic noise signals and does not require filters in this case.

\section{Acknowledgments}

We want to express our deepest gratitude to the reviewers. We believe our manuscript was greatly strengthened in responding to their valuable comments and suggestions.

This work was supported by the Ministerio de Ciencia e Innovación projects numbers DPI201127567-C02 and DPI2011-28033-C03-01.

\section{References}

1. Burton, T.; Sharpe, D.; Jenkins, N.; Bossanyi, E. Wind Energy Handbook; Wiley: Chichester, UK, 2001.

2. Zinger, D.; Muljadi, E. Annualized wind energy improvement using variable speeds. IEEE Trans. Ind. Appl. 1997, 33, 1444-1447.

3. Kusiak, A.; Zhang, Z. Control of wind turbine power and vibration with a data-driven approach. Renew. Energy 2012, 43, 73-82.

4. Hassan, H.M.; Eishafei, A.L.; Farag, W.A.; Saad, M.S. A robust LMI-based pitch controller for large wind turbines. Renew. Energy 2012, 44, 63-71.

5. Sandquist, F.; Moe, G.; Anaya-Lara, O. Individual pitch control of horizontal axis wind turbines. J. Offshore Mech. Arctic Eng.-Trans. ASME 2012, 134, doi:10.1115/1.4005376.

6. Joo, Y.; Back, J. Power regulation of variable speed wind turbines using pitch control based on disturbance observer. J. Electr. Eng. Technol. 2012, 7, 273-280.

7. Diaz de Corcuera, A.; Pujana-Arrese, A.; Ezquerra, J.M.; Segurola, E.; Landaluze, J. H-infinity based control for load mitigation in wind turbines. Energies 2012, 5, 938-967.

8. Soliman, M.; Malik, O.P.; Westwick, D.T. Multiple Model MIMO Predictive Control for Variable Speed Variable Pitch Wind Turbines. In Proceedings of the American Control Conference, Baltimore, MD, USA, 30 June-2 July 2010.

9. Jonkman, J. NWTC Design Codes (FAST). Available online: http://wind.nrel.gov/designcodes/ simulators/fast/ (accessed on 8 March 2012).

10. Boukhezzar, B.; Lupu, L.; Siguerdidjane, H.; Hand, M. Multivariable control strategy for variable speed, variable pitch wind turbines. Renew. Energy 2007, 32, 1273-1287. 
11. Jonkman, J.M.; Butterfield, S.; Musial, W.; Scott, G. Definition of a 5-MW Reference Wind Turbine for Offshore System Development; Technical Report NREL/TP-500-38060; National Renewable Energy Laboratory: Golden, CO, USA, 2009.

12. Slootweg, J.; Polinder, H.; Kling, W. Dynamic Modelling of a Wind Turbine with Doubly Fed Induction Generator. In Proceedings of the Power Engineering Society Summer Meeting, 15-19 July 2001; Volume 1, pp. 644-649.

13. Song, Y.; Dhinakaran, B.; Bao, X. Variable speed control of wind turbines using nonlinear and adaptive algorithms. J. Wind Eng. Ind. Aerodyn. 2000, 85, 293-308.

14. De Battista, H.; Puleston, P.; Mantz, R.; Christiansen, C. Sliding mode control of wind energy systems with DOIG-power efficiency and torsional dynamics optimization. IEEE Trans. Power Syst. 2000, 15, 728-734.

15. Khezami, N.; Braiek, N.B.; Guillaud, X. Wind turbine power tracking using an improved multimodel quadratic approach. Int.Soc. Autom. Trans. 2010, 49, 326-334.

16. Acho, L.; Vidal, Y.; Pozo, F. Robust variable speed control of a wind turbine. Int. J. Innov. Comput. Inf. Control 2010, 6, 1925-1933.

17. Beltran, B.; Ahmed-Ali, T.; Benbouzid, M. High-order sliding-mode control of variable-speed wind turbines. IEEE Trans. Ind. Electr. 2009, 56, 3314-3321.

18. Manjock, A. Design Codes FAST and ADAMS for Load Calculations of Onshore Wind Turbines, 2005; National Renewable Energy Laboratory (NREL): Golden, CO, USA, 2005.

19. Beltran, B.; Ahmed-Ali, T.; El Hachemi Benbouzid, M. Sliding mode power control of variable-speed wind energy conversion systems. IEEE Trans. Energy Convers. 2008, 23, 551-558.

20. Bhat, S.; Bernstein, D. Finite-Time Stability of Homogeneous Systems. In Proceedings of the American Control Conference, Albuquerque, NM, USA, 4-6 June 1997; Volume 4, pp. 2513-2514.

21. Beaty, H.W. Handbook of Electric Power Calculations, 3rd ed.; McGraw-Hill: New York, NY, USA, 2001; Volume 1.

22. Spong, M.W.; Vidyasagar, M. Robot Dynamics and Control; John Wiley and Sons: Hoboken, NJ, USA, 1989.

23. Pao, L.; Johnson, K. A Tutorial on the Dynamics and Control of Wind Turbines and Wind Farms. In Proceedings of the American Control Conference, Boulder, CO, USA, 10-12 June 2009; pp. 2076-2089.

24. Hayman, G. NWTC Design Codes (MCrunch). Available online: http://wind.nrel.gov/designcodes/ postprocessors/mcrunch/ (accessed on 6 June 2012).

25. Malcolm, D.J.; Hansen, A.C. WindPACT Turbine Rotor Design Study; Technical Report NREL/SR 500-32495; National Renewable Energy Laboratory: Golden, CO, USA, 2002.

26. Brown, L.J.; Zhang, Q. Periodic disturbance cancellation with uncertain frequency. Automatica 2004, 40, 631-637.

27. Wu, B.; Bodson, M. Direct adaptive cancellation of periodic disturbances for multivariable plants. IEEE Trans. Speech Audio Process. 2003, 11, 538-548.

(c) 2012 by the authors; licensee MDPI, Basel, Switzerland. This article is an open access article distributed under the terms and conditions of the Creative Commons Attribution license (http://creativecommons.org/licenses/by/3.0/). 